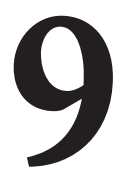

\title{
DETERMINANTES E IMPACTO EN LOS SALARIOS DEL DESAJUSTE EDUCATIVO
}

(DETERMINANTS AND WAGE EFFECTS OF EDUCATIONAL MISMATCH IN SPAIN)

Iñaki Iriondo Múgica

Universidad Complutense de Madrid

DOI: $10.5944 / e d u c X X 1.30580$

\section{Cómo referenciar este artículo/How to reference this article:}

Iriondo Múgica, I. (2022). Determinantes e impacto en los salarios del desajuste educativo. Educación XX1, 25(1), 219-249. https://doi.org/10.5944/educXX1.30580

Iriondo Múgica, I. (2022). Determinants and wage effects of educational mismatch in Spain. Educación XX1, 25(1), 219-249. https://doi.org/10.5944/educXX1.30580

\section{RESUMEN}

En este trabajo se analiza el impacto de tres indicadores alternativos del desajuste educativo (horizontal, vertical y de habilidades) sobre los salarios de una muestra de titulados universitarios que recientemente finalizaron sus estudios en España. En la literatura se han propuesto dos enfoques alternativos para explicar el desajuste educativo: la teoría de la asignación, que plantea que la productividad de los trabajadores está limitada por las características de los empleos, de forma que los trabajadores sobreeducados infrautilizan su capacidad y por tanto ganan unos salarios inferiores, y la teoría de la heterogeneidad en las habilidades, que mantiene que el desajuste educativo es aparente en la medida en que los trabajadores sobreeducados tienen una menor dotación de habilidades y conocimientos. Con el ánimo de tratar de ofrecer alguna luz al debate teórico se han analizado los datos de 2019 de la Encuesta de Inserción Laboral de Titulados Universitarios, 
elaborada por el INE. En el análisis empírico se estima el impacto en los salarios de los tres tipos de desajuste educativo. Además se utiliza el estimador de efectos fijos al objeto de controlar la heterogeneidad individual en la evaluación del impacto del desajuste educativo en los salarios. Los resultados del trabajo indican que los graduados sobreeducados sufren una penalización sustancial y estadísticamente significativa en sus retribuciones tanto en la estimación por mínimos cuadrados ordinarios como en el modelo de efectos fijos. Por tanto, desde el punto de vista económico el desajuste educativo vertical representa un despilfarro de recursos. Los poderes públicos deberían crear las condiciones para fortalecer la demanda de trabajo cualificado de forma que el mercado pueda absorber la oferta creciente de titulados que ha producido el sistema universitario español en las últimas décadas.

\section{PALABRAS CLAVE}

Enseñanza superior, sobreeducación, desajuste de habilidades, desajuste educativo, salario, capital humano

\section{ABSTRACT}

This paper analyzes the impact of three alternative measures of educational mismatch (overeducation, horizontal mismatch and overskilling) on the wages of a sample of Spanish university graduates who have recently finished their studies. In the literature, two alternative theories have been proposed to explain the educational mismatch: the allocation theory, which states that worker productivity is limited by job characteristics, so that overeducated workers underutilize their skills and therefore earn lower wages; and the theory of skill heterogeneity which states that the educational mismatch is apparent to the extent that overeducated workers have a lower endowment of knowledge and skills. With the aim of trying to shed some light on this theoretical debate, the 2019 data from the "University Graduate Job Placement Survey", carried out by the Spanish National Institute of Statistics (INE), has been analyzed. For the empirical analysis we have estimated the wage penalties of the three types of educational mismatch. In order to control for individual heterogeneity in estimating the wage effects a fixed effects model is used. The results of the empirical work indicate that the overeducated graduates suffer a substantial and statistically significant wage penalty both in the fixed effects model and in the ordinary least squares model. From the economic point of view, overeducation represents a waste of resources. Therefore, public authorities should create the conditions to strengthen the demand for qualified labor so that the labor market can 
absorb the growing supply of graduates that the Spanish university system has produced in recent decades.

\section{KEYWORDS}

Higher education, overeducation, overskilling, educational mismatch, wages, human capital

\section{INTRODUCCIÓN}

Según Eurostat (2020) España es el país de la Unión Europea en el que la incidencia de la sobrecualificación en 2019 es más elevada. Mientras que la incidencia del desajuste educativo horizontal se sitúa en España $(27.8 \%)$ en torno a la media de la Unión Europea (27.9\%), los resultados del desajuste vertical sitúan a España $(36,6 \%)$ en una posición desfavorable en comparación con el conjunto de la Unión a 27 miembros (21.9\%). Estos datos indican que la asignación del empleo es ineficiente en la medida en que las empresas no pueden aprovechar el potencial productivo de nuestros titulados. En términos personales el desajuste educativo genera frustración e insatisfacción, y desde un punto de vista privado y social representa un despilfarro de recursos.

En la literatura especializada se definen tres modalidades de desajuste educativo: vertical, horizontal y de habilidades. Se entiende por desajuste vertical o sobreeducación aquella situación en la que el graduado desempeña un empleo que requiere un nivel de estudios inferior al que posee. Por su parte, el desajuste educativo horizontal se produce cuando el trabajador desempeña un empleo no relacionado con su área de estudios. Por último, el desajuste de habilidades hace referencia a aquella situación en la que el titulado no utiliza en su puesto de trabajo los conocimientos y habilidades adquiridos en su educación formal.

El objetivo de este trabajo es triple. Por un lado se va a estudiar la incidencia de las tres modalidades de desajuste en una muestra de titulados universitarios que ha salido recientemente del sistema educativo. Por otro lado, se va a evaluar el impacto del desajuste educativo horizontal, vertical y de habilidades en los salarios. Por último, se van a analizar los factores que influyen en la probabilidad de estar afectado por los distintos tipos de desajuste.

En el análisis empírico se va a utilizar la última edición de la Encuesta de Inserción Laboral de Titulados Universitarios elaborada por el Instituto 
Nacional de Estadística. Esta encuesta proporciona información del proceso de transición al mercado de trabajo de una muestra de alrededor de 30.000 titulados de las universidades españolas, y tiene una extraordinaria riqueza para investigar el desajuste educativo en los años inmediatamente posteriores a la finalización de sus estudios.

Como principales aportaciones del trabajo habría que señalar en primer lugar que se va a proporcionar evidencia empírica para evaluar el carácter temporal o permanente del desajuste educativo. Además, se va a tratar de arrojar alguna luz al debate entre las teorías de la asignación y de la heterogeneidad de las habilidades que hacen hincapié, respectivamente, en los factores de oferta y de demanda en la interpretación del problema. Para ello se estimarán ecuaciones de ingresos en las que se van a comparar los resultados del estimador por mínimos cuadrados ordinarios (MCO), con el modelo de efectos fijos, con el que se controla la heterogeneidad individual, enfoque, por otra parte, no muy habitual en la literatura. Por último, la inclusión en las estimaciones, de los tres indicadores de desajuste educativo, permite comprender las relaciones existentes entre las tres dimensiones del problema.

Como principales resultados habría que señalar que 5 años después de salir del sistema educativo, el desajuste afecta en torno a una quinta parte de los titulados universitarios, colectivo para el que el problema puede tener un carácter permanente. Por otro lado, los resultados de la estimación de las ecuaciones de ingresos sugieren que las características de los empleos limitan el aprovechamiento de la productividad de los universitarios sobreeducados. Por último, se observa que los graduados procedentes de entornos económicos desfavorables tienen una mayor probabilidad de estar afectados por el desajuste vertical que, por otra parte, varía de forma muy notable en función del ámbito de estudio del titulado.

\section{REVISIÓN DE LA LITERATURA}

Desde el trabajo seminal de Freeman (1976) una parte de la literatura especializada ha tratado de determinar si la sobreeducación tiene un carácter temporal o permanente. Algunos autores interpretan el desajuste educativo como una fricción del mercado laboral, donde los titulados universitarios aceptan temporalmente empleos de inferior cualificación hasta acceder a un puesto acorde con su nivel de estudios (Kucel y Vilalta-Bufí, 2019). De forma similar, otros autores plantean que el desajuste educativo surge como consecuencia de la existencia de información imperfecta (Hartog, 2000). También se ha analizado la cuestión en el marco del modelo de las carreras profesionales y se investiga si los trabajadores sobreeducados tienen una mayor probabilidad de ser promocionados a un puesto de superior categoría 
(Sichermar y Galor, 1990; Alba-Ramírez, A. y Blázquez, M., 2002). La reducción del desajuste educativo en los primeros años de transición de los universitarios al mercado de trabajo, en los que la movilidad interna y externa es elevada, ha llevado a algunos autores a afirmar que la sobreeducación es un fenómeno temporal (Sicherman, 1991; Alba, 1993). En la misma línea se ha argumentado que los recién graduados tienen una inferior dotación de otras características no observables del capital humano, que se compensa a medida que los titulados acumulan experiencia en el mercado de trabajo. Sin embargo, la evidencia empírica aportada por otros autores les lleva a concluir que para una parte importante de los graduados el desajuste educativo tiene un carácter persistente (García-Serrano y Malo, 1996; Battu et al, 1999; Dolton y Vignoles, 2000; Rubb, 2003; Frenette, 2004).

Otra línea de investigación fructífera analiza el impacto del desajuste educativo en los salarios (Duncan y Hoffman, 1981; Hartog, 2000; Leuven y Oosterbeck, 2001; y McGuinness, 2006). Desde la perspectiva de la teoría del capital humano (Becker, 1964), la dotación de conocimientos y habilidades de cada individuo determinan su productividad y su retribución. En el caso de que la oferta de un determinado tipo de trabajadores crezca más rápidamente que su demanda, los salarios relativos de este colectivo tenderán a caer, sin que ello afecte al grado de utilización de sus habilidades y conocimientos (Green et. al, 1999; Biagi, Castaño y Di Pietro, 2020; Green y Henseke, 2021).

Por su parte Thurow (1976) en su "modelo de competencia por los puestos de trabajo" hace hincapié en la demanda y no en la oferta a la hora de describir el funcionamiento del mercado de trabajo. En su opinión, la productividad y los salarios no dependen de las características del individuo, sino de las del puesto de trabajo que ocupa. De esta forma, los trabajadores no compiten en salarios, sino por el acceso a los empleos. En el caso de que la oferta de una cierta cualificación sea superior a las vacantes de estos empleos, una parte de los individuos se verá obligada a aceptar trabajos de inferior cualificación, percibiendo los salarios habitualmente pagados en esos trabajos. Sattinger (1993) en esta misma línea plantea la "teoría de la asignación" según la cual los trabajadores son asignados a los empleos en función de sus habilidades y conocimientos. En el caso de que un trabajador con unas determinadas habilidades esté ocupando un puesto de inferior cualificación, el puesto de trabajo impondrá una restricción en la productividad que el trabajador puede alcanzar (Allen y De Weert, 2007). En este caso, la limitación vendría por el puesto de trabajo y no por la productividad del trabajador.

Como contraposición, desde el lado de la oferta se ha propuesto la "teoría de la heterogeneidad en las habilidades" (Green y Mcintosh, 2007) 
que parte de la base de que entre personas con el mismo nivel de estudios hay una gran heterogeneidad con relación a la capacidad y dotación de habilidades. En este sentido, se argumenta que la sobreeducación es aparente si los individuos que ocupan puestos de menor cualificación están en la cola inferior de la distribución de capacidad (Di Pietro y Urwin, 2006).

Al objeto de discriminar entre la teoría de la asignación y la teoría de la heterogeneidad de las habilidades, algunos autores proponen introducir en las ecuaciones de ingresos variables relativas al desajuste educativo y al de habilidades (Allen y van der Velden, 2001). Se argumenta que si el coeficiente del desajuste educativo se reduce notablemente o se anula al introducir el desajuste de habilidades, se confirma que la penalización salarial de la sobreeducación se asocia a la no utilización de los conocimientos y habilidades del trabajador, por lo que la teoría de la asignación ofrecerá una explicación plausible del problema (Di Pietro y Urwin, 2006; Green y McInstosh, 2007; Allen y De Weert, 2007; Green y Zhu, 2010; McGuinness y Sloane, 2011; Nieto y Ramos, 2017). Sin embargo, esta literatura no ha tenido en cuenta que aunque desajuste educativo y de habilidades están correlacionados, la no utilización de los conocimientos y habilidades del trabajador no siempre se explica por la sobreeducación y, por tanto, no tiene por qué resultar en una penalización salarial, como cuando existe desajuste horizontal voluntario. Esto hace que la correlación entre salarios y desajuste vertical sea más fuerte que con el desajuste horizontal y de habilidades, por lo que se recomienda abordar el contraste de las teorías con otras técnicas complementarias, como los datos de panel. En el apartado empírico se volverá a retomar esta cuestión.

Gran parte de los trabajos que estiman el impacto del desajuste educativo en los salarios han sido criticados por no tener en cuenta el problema de la omisión de la capacidad, que puede sesgar al alza la penalización salarial de la sobreeducación (Chevalier, 2003). La estrategia empleada en la literatura para hacer frente al problema ha consistido en el empleo del modelo de efectos fijos. Algunos trabajos, como por ejemplo en Bauer (2002), Frenette (2004) y Tsai (2010), concluyen que la penalización salarial de la sobreeducación que se obtiene en las estimaciones por MCO, se reduce o desaparece cuando se estima por efectos fijos. En cambio, en otros trabajos los resultados no cambian sustancialmente cuando se controlan las diferencias de capacidad individual (Dolton y Silles, 2008; Korpi y Tahlin, 2009; Iriondo y Pérez-Amaral, 2016; y McGuinnes et al., 2018).

Otra línea de investigación que está recibiendo un interés creciente es el estudio del desajuste horizontal, que tiene lugar cuando el individuo trabaja fuera del campo de estudios en el que se ha formado (Almasi et al., 2020; y 
Choi y Hur, 2020). Nordin, Persson y Rooth (2010) comprueban que la mayor parte de los graduados en Biología, Matemáticas, Físicas, Ingeniería, Historia, Periodismo, Humanidades, entre otras titulaciones, están débilmente emparejados con su área de conocimiento. Los autores señalan que el desajuste horizontal puede ser involuntario, en la medida en que las vacantes disponibles en su propio campo de estudios se hayan agotado, o puede ser voluntario, fruto de un mejor conocimiento de los atributos pecuniarios o no pecuniarios asociados a algunos empleos fuera del área propia de estudios. En la estimación del modelo, los autores encuentran que el desajuste horizontal tiene un impacto negativo en los salarios. En cambio, Budría y Moro-Egido (2008) observan que el desajuste horizontal no tiene un efecto significativo en los ingresos, una vez que se controla el desajuste vertical. En un trabajo más reciente, Somers et al. (2019) revisan la literatura sobre el desajuste educativo horizontal publicada entre 1995 y 2015. Los autores afirman que, dependiendo de la definición empleada, el desajuste horizontal afecta a entre un $21 \%$ y un $46 \%$ de los trabajadores. A su vez constatan que la prevalencia del desajuste horizontal varía notablemente por campos de estudio.

El interés creciente por el estudio del desajuste educativo se manifiesta en un desarrollo de la investigación empírica del fenómeno en muchos países distintos de Europa y Estados Unidos, entre los que están, por mencionar unos ejemplos, Rusia (Rudakov et al., 2019), Bosnia-Herzegovina (Veselinović, Mangafić y Turulja, 2020), Australia (Li, Harris y Sloane, 2018), Canadá (Banerjee, Verma y Zhang, 2019) o Corea del Sur (Park, 2018).

La investigación en España acerca del desajuste educativo se remonta a los años noventa del siglo pasado (Alba, 1993). Desde entonces un grupo amplio de investigadores han abordado, entre otros temas, el estudio de la penalización salarial de la sobrecualificación y su evolución en el tiempo (Murillo, Rahona y Salinas, 2012), la hipótesis de la heterogeneidad en las habilidades (Nieto y Ramos, 2017), la sobreeducación desde la perspectiva de la teoría de la señalización (García-Mainar y Montuenga, 2019), el impacto del emprendimiento y el prestigio académico de los programas educativos en la reducción del desajuste educativo (KUCEL y Vilalta-Bufí, 2019) y los determinantes del desajuste educativo horizontal y vertical (RodríguezEsteban, Vidal y Vieira, 2019; y Rodríguez-Esteban y Vidal, 2020).

\section{METODOLOGÍA}

El objetivo de este apartado es presentar las ecuaciones de ingresos con las que se va a estudiar la asociación existente entre las distintas modalidades de desajuste educativo y los salarios. Al objeto de tratar de ofrecer alguna 
luz al debate teórico anterior, se va a proceder a la estimación de distintas especificaciones de la siguiente ecuación general de los salarios:

$$
w_{i}=\alpha+\beta_{1} \text { over }_{i}+\beta_{2} \text { horiz }_{i}+\beta_{3} \text { nousk }_{i}+X_{k i} \gamma_{k}+\varepsilon_{i}
$$

Donde $w_{\mathrm{i}}$ es el logaritmo de los salarios del graduado "i", over es una variable dicotómica que toma valor 1 si el individuo está sobreeducado y 0 si no lo está; horiz $z_{\mathrm{i}}$ es una variable dicotómica que toma valor 1 si el individuo trabaja fuera de su área de estudios y 0 si no padece desajuste horizontal; nousk $_{\mathrm{i}}$ es una variable dicotómica que toma valor 1 si el individuo no utiliza en su empleo los conocimientos y habilidades adquiridos en la universidad y 0 en caso contrario; $X_{\mathrm{ki}}$ es un vector que contiene otras " $\mathrm{k}$ " variables explicativas (sexo, edad, nivel de estudios de los padres, beca general, beca de excelencia, máster, universidad privada, universidad a distancia, trabajo a tiempo parcial, discapacidad reconocida superior al 33\%, nacionalidad extranjera, Comunidad Autónoma y titulación) y, por último, $\varepsilon_{\mathrm{i}}$ representa el término de error. Los coeficientes a estimar en la ecuación son: $\beta_{1}$, que representa la penalización salarial $\left(\beta_{1}<0\right)$ que sufre el universitario sobreeducado, $\beta_{2}$, que representa el impacto en los ingresos del desajuste horizontal $\left(\beta_{2}<0\right)$, $\beta_{3}$, que mide la penalización en los salarios de no utilizar las habilidades y conocimientos adquiridos en la universidad $\left(\beta_{3}<0\right), \gamma_{\mathrm{k}}$, que representa los coeficientes del resto de los controles y, finalmente, $\alpha$ que es la constante.

La teoría de la heterogeneidad en las habilidades parte de la base de que los trabajadores sobreducados tienen inferior capacidad o cualificaciones menos demandadas en el mercado de trabajo. En la medida en que la capacidad individual no es observable y puede estar correlacionada con la sobreeducación, la omisión de esa variable hace que el estimador de mínimos cuadrados ordinarios sea inconsistente. Un procedimiento habitual para corregir la endogeneidad que genera la omisión de la capacidad es la estimación con datos de panel introduciendo en la ecuación salarial efectos fijos individuales (Leuven y Oosterbeek, 2011). Supongamos que deseamos estimar la siguiente ecuación:

$$
w_{i t}=\mu+\beta \text { over }_{i t}+X_{k i t} \gamma_{k}+\delta \text { capacidad }_{i}+u_{i t}
$$

Donde a diferencia del modelo anterior se introduce la dimensión temporal, capacidad $_{\mathrm{i}}$ representa la capacidad individual y mide el impacto de la capacidad en los salarios (). El sesgo que genera la omisión de la capacidad en la estimación por MCO es:

$$
E\left(\beta^{*}\right)=\beta+\delta \frac{\operatorname{Cov}(\text { over,capacidad })}{\operatorname{Var}(\text { over })}
$$


En el caso de que la sobreeducación esté correlacionada negativamente con la capacidad y la capacidad positivamente con los ingresos, la estimación del efecto de la sobreeducación en los salarios estará sesgada al alza. La estrategia de identificación que habitualmente se emplea para corregir el problema, es mediante la estimación en desviaciones respecto de la media de cada individuo a lo largo del tiempo, siguiendo la siguiente expresión:

$$
\left(w_{i t}-\bar{w}_{i}\right)=\beta\left(\text { over }_{i t}-\overline{\text { over }}_{i}\right)+\left(X_{k i t}-\bar{X}_{k i}\right) \gamma_{k}+\left(u_{i t}-\bar{u}_{i}\right)
$$

Las variables que no cambian a lo largo del tiempo, como el sexo, la capacidad o los conocimientos y habilidades adquiridos por el graduado en la universidad, desaparecen del modelo en diferencias.

El análisis de los salarios se va a complementar con la estimación de un modelo logit con el que se van a investigar los determinantes de los distintos tipos de desajuste educativo (vertical, horizontal y de habilidades). Por ejemplo, en el estudio del desajuste vertical, la probabilidad de que el graduado esté sobreeducado dependerá, entre otras variables explicativas, del ámbito de estudio del titulado y adopta la forma de la función logística:

$$
\operatorname{Pr}\left(y_{i}=1 \mid x_{i}\right)=\frac{\exp \left(\beta_{0}+\beta_{1} \text { ámbito }_{i}+X_{k i} \gamma_{k}\right)}{1+\exp \left(\beta_{0}+\beta_{1} \text { ámbito }_{i}+X_{k i} \gamma_{k}\right)}
$$

Al objeto de calcular los efectos marginales debemos obtener las derivadas parciales de la probabilidad de que con relación a la variable explicativa de interés. En el caso de que la variable dependiente sea binaria, como en el caso de la variable ámbito, el efecto marginal se calcula de la siguiente forma:

$$
\frac{\partial \operatorname{Pr}\left(y_{i}=1 \mid x_{k i}\right)}{\text { dámbito }}=\frac{\exp \left(\beta_{0}+\beta_{1}+X_{k i} \gamma_{k}\right)}{1+\exp \left(\beta_{0}+\beta_{1}+X_{k i} \gamma_{k}\right)}-\frac{\exp \left(\beta_{0}+X_{k i} \gamma_{k}\right)}{1+\exp \left(\beta_{0}+X_{k i} \gamma_{k}\right)}
$$

\section{LOS DATOS}

La fuente de información estadística utilizada en este trabajo es la Encuesta de Inserción Laboral de Titulados Universitarios (EILU) elaborada por el Instituto Nacional de Estadística (INE, 2020). La EILU investiga la transición de la universidad al mercado de trabajo de 31651 titulados de las universidades españolas. La encuesta proporciona información sobre el tiempo transcurrido hasta el acceso al empleo, las características de los trabajos desempeñados, la adecuación de los estudios al mercado laboral, la movilidad y, entre otras cuestiones, los periodos de desempleo e inactividad laboral. La muestra analizada en este artículo se corresponde a la cohorte 
de titulados del curso 2013-2014, y el trabajo de campo se desarrolló entre los meses de julio y diciembre de 2019 , antes del desencadenamiento de la crisis del COVID-19.

La EILU tiene una enorme riqueza y proporciona información sobre las características personales de los titulados (entre otras, sexo, edad, nacionalidad, nivel educativo de los padres, discapacidad, Comunidad Autónoma), su proceso de aprendizaje (rama, ámbito de estudio y titulación, tipo de universidad, becas o la formación de postgrado), y su inserción al mercado de trabajo (situación laboral, situación profesional, percepción subjetiva de la adecuación entre formación y empleo, y salarios).

Las variables de interés de este trabajo son los salarios y las variables que miden el desajuste educativo, que se han construido a partir de las siguientes preguntas de la encuesta:

- Sueldo mensual neto del primer trabajo o de su empleo actual en el momento en el que empezó (PR_SUELDO), y sueldo mensual neto de su empleo actual (TR_SUELDO). Se ha creado una variable discreta a partir de los valores medios en los que se han estratificado los salarios ("Menos de 700 euros", "De 700 a 999 euros", "De 1000 a 1499 euros", "De 1500 a 1999 euros", "De 2000 a 2499 euros", "De 2500 a 2999 euros", "De 3000 euros en adelante").

- Nivel de formación más apropiado para realizar el trabajo actual (TR_ D19) o su primer empleo (PR_NIVEL). A partir de estas preguntas se ha creado una variable dicotómica para medir la percepción subjetiva de la sobreeducación (over), que toma valor 1 en el caso de que el titulado responda que el nivel de formación más adecuado es "Formación profesional de grado superior", "Formación profesional de grado medio/ bachillerato" o "ESO, EGB,... etc", y toma valor 0 en el caso de que el titulado responda que el nivel de formación más adecuado es "Doctorado o postdoctorado" o "Título universitario (excepto doctorado o postdoctorado)". Por tanto, en este trabajo se define la sobreeducación como aquella situación en la que el graduado cuenta con un nivel de estudios superior al requerido por su puesto de trabajo, que en el caso de los titulados universitarios, se hace operativo cuando el empleo requiere un nivel de estudios inferior o igual a la "Formación profesional de grado superior".

- Área de estudio más apropiada para el trabajo actual (TR_D20) o su primer empleo (PR_AREA). A partir de estas variables se ha construido una variable dicotómica que mide el desajuste horizontal (horiz). La variable toma valor 1 en el caso de que el graduado 
responda que el área de estudios más apropiada para su empleo es "Un área totalmente diferente" o "Ningún área en particular", y toma valor 0 en el caso de que el área más apropiada sea "Exclusivamente su propia área de estudios" o "Su propia área o alguna relacionada"

- Se hace uso en el trabajo actual (TR_D21) o en su primer empleo $\left(P R_{-} C O N O C\right)$ de los conocimientos y habilidades adquiridos en estos estudios. A partir de esta pregunta se ha creado una variable dicotómica que mide el desajuste de habilidades (nousk), que adopta el valor 1 si el graduado responde negativamente y 0 si responde afirmativamente.

Las variables relativas al desajuste educativo vertical (over), horizontal (horiz) y de habilidades (nousk) se construyen a partir de las respuestas subjetivas de los encuestados. Los indicadores subjetivos han sido utilizados de forma frecuente en la literatura del desajuste educativo. Por ejemplo, Di Pietro y Urwin (2006) concluyen que sus resultados "confirman la opinión de que las percepciones de los empleados sobre los requisitos educativos de un trabajo en particular son indicadores más fiables de la verdadera naturaleza de los empleos". No obstante, este tipo de indicadores no está exento de problemas, entre los cuales habría que señalar que la valoración subjetiva sobre los requerimientos educativos de los empleos puede variar entre individuos.

En la Tabla 1 se presenta un resumen de los estadísticos descriptivos de las principales variables. Entre otros resultados cabe señalar que el $57.0 \%$ de los graduados encuestados son mujeres y un $1.2 \%$ son personas con discapacidad. En el $28.6 \%$ de los casos, la madre del graduado tenía formación universitaria y en un 30.6\% el padre tenía estudios superiores. El $14.8 \%$ de los graduados había estudiado en una universidad privada y el $47.5 \%$ posteriormente había cursado un máster. En cuanto a la rama de conocimiento, predominan los titulados de "Ciencias sociales y jurídicas" (45.8\%). La tasa de empleo en 2019 es elevada y se sitúa en el 85.7\%, coherente con la recuperación que la economía española estaba viviendo desde 2014. En la misma línea los salarios netos de los graduados habían aumentado por término medio en un $51.9 \%$ en términos nominales.

La evolución de las variables representativas del desajuste educativo indica que para una parte importante de los titulados, el desajuste es un problema temporal. Así, entre el primer empleo y el empleo actual, la sobreeducación se reduce en 16.2 puntos porcentuales, el desajuste horizontal en 9.0 puntos y la no utilización de los conocimientos y habilidades adquiridos en la carrera en 9.3 puntos porcentuales. No obstante, al finalizar el periodo alrededor de una quinta parte de los titulados (21.3\%) 
sigue estando sobreeducado, y aproximadamente una cuarta parte trabajan fuera de su área de conocimiento $(26.2 \%)$ o no utiliza sus conocimientos y habilidades $(24.3 \%)$. Para estos graduados, el desajuste educativo puede tener un carácter permanente.

\section{Tabla 1}

Estadísticos descriptivos

\begin{tabular}{lc}
\hline \multicolumn{1}{c}{ Variables } & Media \\
\hline$\%$ Mujeres & 57.0 \\
\hline$\%$ Discapacidad & 1.2 \\
\hline$\%$ Madre con estudios primarios & 22.3 \\
\hline$\%$ Madre con estudios universitarios & 28.6 \\
\hline$\%$ Padre con estudios primarios & 22.3 \\
\hline$\%$ Padre con estudios universitarios & 30.6 \\
\hline$\%$ Beca general & 38.2 \\
\hline$\%$ Beca de excelencia & 4.4 \\
\hline$\%$ Universidad privada & 14.8 \\
\hline$\%$ Formación de postgrado: máster & 47.5 \\
\hline$\%$ Artes y Humanidades & 10.0 \\
\hline$\%$ Ciencias & 8.8 \\
\hline$\%$ Ciencias Sociales y Jurídicas & 45.8 \\
\hline$\%$ Ingeniería y Arquitectura & 21.2 \\
\hline$\%$ Ciencias de la Salud & 14.2 \\
\hline$\%$ Tasa de empleo actual & 85.7 \\
\hline Salario (primer empleo) & 1056.0 \\
\hline Salario (empleo actual) & 1604.4 \\
\hline$\%$ Desajuste vertical (primer empleo) & 37.5 \\
\hline$\%$ Desajuste vertical (empleo actual) & 21.3 \\
\hline$\%$ Desajuste horizontal (primer empleo) & 35.2 \\
\hline \% Desajuste horizontal (empleo actual) & 26.2 \\
\hline Número de observaciones & 33.6 \\
\hline
\end{tabular}

Nota. Para simplificar la presentación de la tabla no se incluyen las desviaciones típicas de las variables que, al tratarse en su gran mayoría de variables dicotómicas, se pueden calcular como la raíz cuadrada de p*(1-p), siendo "p" la probabilidad de que $\mathrm{X}=1$. Las desviaciones típicas de las dos únicas variables discretas de la tabla son 492.0 euros en el "salario del primer empleo" y 632.9 euros en el "salario del empleo actual".

Fuente. Encuesta de Inserción Laboral de Titulados Universitarios de 2019 (INE). Elaboración propia 
La valoración anterior se confirma con el análisis de la matriz de transiciones (véase la Tabla 2). La tabla mide los cambios de estatus entre el primer empleo y el empleo actual, con relación a los tres indicadores de desajuste educativo. Por ejemplo, con relación al desajuste vertical (panel superior), en la primera fila ("nivel adecuado") se muestra la situación en el empleo actual de aquellos graduados que estaban en un puesto acorde con su formación en el primer empleo. Los resultados revelan que el 94.5\% de estos titulados seguían en la actualidad en empleos acordes con su formación, mientras que un 5.5\% del total empeoran su situación al clasificarse como sobreeducados 5 años después de terminar sus estudios. De forma similar, en la segunda fila ("sobreeducado") se muestra el estatus en el empleo actual de aquellos titulados que afirman estar sobreeducados en su primer empleo. En este caso se observa que el 50.2\% de los graduados que estaban sobreeducados en su primer empleo, desempeñan un puesto acorde con su formación en el empleo actual. Sin embargo, el 49.8\% de los titulados que estaban sobrecualificados en su primer empleo siguen estando sobreeducados en el empleo actual, colectivo para los que el desajuste educativo puede tener un carácter permanente. La tercera fila ("total") informa de la situación en el empleo actual del total de los graduados, independientemente de su situación con relación al desajuste educativo en el primer empleo y muestra que, cinco años después de terminar sus estudios universitarios, el 78.7\% de los titulados desempeñan empleos acordes con su nivel de estudios, mientras que el $21.3 \%$ trabaja en puestos que requieren un nivel de estudios inferior.

En los otros dos paneles inferiores se analizan las transiciones entre el primer empleo y el empleo actual del desajuste horizontal y del desajuste de habilidades, respectivamente. El patrón de resultados es bastante similar a lo descrito con relación al desajuste vertical. Por un lado, el 91.1\% de los titulados que desempeñaban un empleo en un área adecuada en su primer empleo siguen en la misma situación 5 años después. Por otro lado, el 91.4\% de los graduados que señalaban en la encuesta utilizar en su primer empleo los conocimientos y habilidades adquiridos en sus estudios, manifiestan utilizarlos en sus empleos actuales.

El análisis de la segunda fila de estos paneles inferiores revela una mejoría con relación al empleo actual en el $40.3 \%$ de los graduados que trabajaban en un área ajena a su formación en su primer empleo y el $42.6 \%$ de los que no utilizaban sus conocimientos y habilidades en su primer trabajo, para quienes el desajuste se manifiesta como un problema temporal. Sin embargo para el 59.7\% de quienes sufrían desajuste horizontal en el primer empleo y el $57.4 \%$ de los que no usaban sus habilidades y conocimientos en su primer puesto de trabajo, la situación no cambia en el empleo actual y el desajuste educativo puede tener un carácter permanente. 
Tabla 2

Matriz de transiciones de los indicadores de desajuste educativo

\begin{tabular}{|c|c|c|c|c|}
\hline \multicolumn{2}{|c|}{ A. Desajuste vertical } & \multicolumn{3}{|c|}{ Empleo actual } \\
\hline & & Nivel adecuado & Sobreeducado & Total \\
\hline \multirow{3}{*}{$\begin{array}{l}\text { Primer } \\
\text { empleo }\end{array}$} & Nivel adecuado & 94.54 & 5.46 & 100.00 \\
\hline & Sobreeducado & 50.20 & 49.80 & 100.00 \\
\hline & Total & 78.68 & 21.32 & 100.00 \\
\hline \multirow{2}{*}{\multicolumn{2}{|c|}{ B. Desajuste horizontal }} & \multicolumn{3}{|c|}{ Empleo actual } \\
\hline & & Área adecuada & $\begin{array}{l}\text { Desajuste } \\
\text { horizontal }\end{array}$ & Total \\
\hline \multirow{3}{*}{$\begin{array}{l}\text { Primer } \\
\text { empleo }\end{array}$} & Área adecuada & 91.08 & 8.92 & 100.00 \\
\hline & Desajuste horizontal & 40.29 & 59.71 & 100.00 \\
\hline & Total & 73.81 & 26.19 & 100.00 \\
\hline \multirow{2}{*}{\multicolumn{2}{|c|}{$\begin{array}{l}\text { C. Utilización de conoc./ } \\
\text { habilidades }\end{array}$}} & \multicolumn{3}{|c|}{ Empleo actual } \\
\hline & & $\begin{array}{l}\text { Se usan los } \\
\text { conoc. }\end{array}$ & $\begin{array}{l}\text { No se usan los } \\
\text { conoc. }\end{array}$ & Total \\
\hline \multirow{3}{*}{$\begin{array}{l}\text { Primer } \\
\text { empleo }\end{array}$} & Se usan los conoc. & 91.40 & 8.60 & 100.00 \\
\hline & No se usan los conoc. & 42.62 & 57.38 & 100.00 \\
\hline & Total & 75.68 & 24.32 & 100.00 \\
\hline
\end{tabular}

Fuente. Encuesta de Inserción Laboral de Titulados Universitarios de 2019 (INE). Elaboración propia

\section{RESULTADOS}

Las Tablas 3, 4 y 5 recogen los resultados de las estimaciones por mínimos cuadrados ordinarios (MCO) del efecto de los tres indicadores de desajuste en los salarios de los graduados. El software utilizado en las estimaciones de las ecuaciones de ingresos y en la regresión logística posterior es Stata/MP versión 15.0. En la primera columna se muestra la estimación de la ecuación de ingresos con relación al primer empleo. En la segunda se hace lo propio con los salarios del empleo actual. En la tercera se agrupan los datos de los dos años. En las dos últimas columnas se utilizan técnicas de datos de panel para estimar las ecuaciones de ingresos. En la cuarta columna se muestran los resultados del modelo de efectos aleatorios y en la quinta del modelo de efectos fijos. En la tabla 3 nuestra variable de interés es la sobreeducación, que en todas las estimaciones presenta un signo negativo y estadísticamente significativo. La penalización salarial de 
la sobreeducación pasa de $-10.2 \%$ en el primer empleo (para transformar el coeficiente de -0.108 a porcentaje debemos calcular la exp[coeficiente], restar la unidad y multiplicar el resultado por 100) al $-18.3 \%$ en el empleo actual. En el modelo agrupado la penalización se sitúa en el $-13.0 \%$. El modelo de efectos aleatorios muestra unos resultados muy similares a los del modelo agrupado, con una penalización salarial de $-12.5 \%$. Por último, en la estimación del modelo de efectos fijos la penalización de la sobreeducación se reduce ligeramente hasta el -8.0\%. Estas estimaciones son similares a las encontradas en la literatura. Por poner un ejemplo, en la revisión de McGuinnes et al. (2018) se analizan 23 trabajos en los que se estima la penalización salarial de la sobreeducación, que se sitúa en media en el $13.6 \%$. En cuanto al resto de los coeficientes, los resultados obtenidos son los que se encuentran habitualmente en la literatura. Llama la atención quizás el reducido efecto salarial de la realización de un máster $(+0.8 \%)$.

La estimación por efectos fijos trata de identificar el impacto de la sobreducación en los salarios de aquellos graduados que cambian de estatus con relación a la sobreeducación entre el primer empleo y el empleo actual, situación que se manifiesta en el $21.5 \%$ de los casos. Esta variabilidad es suficiente para estimar el impacto del desajuste educativo en las retribuciones de los titulados. Por otra parte, la estimación del modelo de efectos fijos permite controlar el sesgo que la omisión de la capacidad (habilidades y conocimientos) del titulado puede generar en la estimación por MCO. Por tanto, la primera conclusión que se puede extraer del examen de los resultados es que el control de las diferencias de capacidad individual no observables reduce en torno a un $40 \%$ el tamaño del coeficiente, pero la penalización salarial sigue siendo sustancial y estadísticamente significativa. En conclusión, los resultados de las estimaciones no confirman la hipótesis de la heterogeneidad de las habilidades e invitan a pensar que las características de los empleos impiden el aprovechamiento de la productividad de los graduados sobreeducados.

En la Tabla 4 se muestran los resultados de la estimación de la ecuación de ingresos en la que la variable de interés es el desajuste horizontal. Al igual que en el caso anterior, los graduados que trabajan fuera del área de especialización de sus estudios universitarios sufren una penalización en sus ingresos estadísticamente significativa aunque de menor tamaño a la encontrada con relación al desajuste vertical. La penalización de los salarios oscila entre el $-5.0 \%$ en el primer empleo y el $-7.8 \%$ en el empleo actual. En el modelo agrupado la penalización asciende al $-5.6 \%$ mientras que en el modelo de efectos fijos baja al $-2.6 \%$, aunque el coeficiente sigue siendo estadísticamente significativo. Por su parte, los resultados de la estimación de la penalización del desajuste de habilidades son muy similares y se sitúan en el modelo agrupado en el $-6.0 \%$ y en el $-3.4 \%$ en el modelo de efectos fijos. 
Estos resultados están en línea con los encontrados por McGuinness et al. (2018) en una revisión de la literatura sobre el desajuste de habilidades, donde concluyen que el impacto sobre los salarios es de menor magnitud que en el caso de la sobreducación, obteniéndose una penalización salarial media del $7,5 \%$.

Tabla 3

Estimación del efecto en los salarios del desajuste vertical

\begin{tabular}{|c|c|c|c|c|c|}
\hline & (1) & (2) & (3) & (4) & (5) \\
\hline variables & $\begin{array}{c}\text { Primer } \\
\text { empleo } \\
\text { (MCO) }\end{array}$ & $\begin{array}{l}\text { Empleo } \\
\text { actual } \\
\text { (MCO) }\end{array}$ & $\begin{array}{l}\text { Modelo } \\
\text { agrupado } \\
\text { (MCO) }\end{array}$ & $\begin{array}{c}\text { Efectos } \\
\text { aleatorios }\end{array}$ & $\begin{array}{c}\text { Efectos } \\
\text { fijos }\end{array}$ \\
\hline over & $-.108 * * *$ & $-.202 * * *$ & $-.139 * * *$ & $-.133 * * *$ & $-.083 * * *$ \\
\hline mujer & $-.055 * * *$ & $-.067 * * *$ & $-.061 * * *$ & $-.062 * * *$ & \\
\hline edad 30 a 34 & -.004 & .002 & -.002 & -.003 & \\
\hline edad $>34$ & $.123 * * *$ & $.091 * * *$ & $.104 * * *$ & $.104 * * *$ & \\
\hline becagen & $-.030 * * *$ & $-.040 * * *$ & $-.035 * * *$ & $-.035 * * *$ & \\
\hline becaexc & .013 & $.077 * * *$ & $.043 * * *$ & $.043 * * *$ & \\
\hline máster & & .001 & $.008 \%$ & $.008 *$ & .009 \\
\hline uprivada & $.035 * * *$ & $.048 * * *$ & $.040 * * *$ & $.041 * * *$ & \\
\hline parcial & $-.359 * * *$ & $-.505 * * *$ & $-.404 * * *$ & $-.399 * * *$ & $-.373 * * *$ \\
\hline año2 & & & $.322 * * *$ & $.325 * * *$ & $.338 * * *$ \\
\hline Constante & $6.966 * * *$ & $7.449 * * *$ & $7.044 * * *$ & $7.042 * * *$ & $7.026 * * *$ \\
\hline $\begin{array}{l}\text { Observacio- } \\
\text { nes }\end{array}$ & 27240 & 24270 & 51510 & 51510 & 51510 \\
\hline $\mathrm{R}^{2}$ & .347 & .443 & .502 & .502 & .423 \\
\hline Individuos & & & & 27907 & 27907 \\
\hline
\end{tabular}

Nota. Las regresiones incluyen además controles sobre el nivel de estudios de los padres, universidad a distancia, discapacidad reconocida superior al 33\%, nacionalidad extranjera, Comunidad Autónoma y titulación.

$* * * \mathrm{p}<0.01, * * \mathrm{p}<0.05, * \mathrm{p}<0.1$

Fuente. Encuesta de Inserción Laboral de Titulados Universitarios de 2019 (INE). Elaboración propia 
Tabla 4

Estimación del efecto en los salarios del desajuste horizontal

\begin{tabular}{|c|c|c|c|c|c|}
\hline & (1) & (2) & (3) & (4) & (5) \\
\hline variables & $\begin{array}{c}\text { Primer } \\
\text { empleo } \\
(\text { MCO) }\end{array}$ & $\begin{array}{c}\text { Empleo } \\
\text { actual } \\
\text { (MCO) }\end{array}$ & $\begin{array}{c}\text { Modelo } \\
\text { agrupado } \\
\text { (MCO) }\end{array}$ & $\begin{array}{l}\text { Efectos } \\
\text { aleatorios }\end{array}$ & $\begin{array}{c}\text { Efectos } \\
\text { fijos }\end{array}$ \\
\hline horiz & $-.051 * * *$ & $-.081 * * *$ & $-.058 * * *$ & $-.055 * * *$ & $-.026 * * *$ \\
\hline mujer & $-.055 * * *$ & $-.067 * * *$ & $-.061 * * *$ & $-.062 * * *$ & \\
\hline edad 30 a 34 & $-.010 *$ & -.005 & $-.009 * *$ & $-.009 * *$ & \\
\hline edad > 34 & $.124 * * *$ & $.090 * * *$ & $.104 * * *$ & $.104 * * *$ & \\
\hline becagen & $-.035 * * *$ & $-.046 * * *$ & $-.040 * * *$ & $-.040 * * *$ & \\
\hline becaexc & $.020 *$ & $.083 * * *$ & $.050 * * *$ & $.050 * * *$ & \\
\hline máster & & $.017 * * *$ & $.018 * * *$ & $.016 * * *$ & $.011 * *$ \\
\hline uprivada & $.041 * * *$ & $.054 * * *$ & $.047 * * *$ & $.047 * * *$ & \\
\hline parcial & $-.373 * * *$ & $-.528 * * *$ & $-.422 * * *$ & $-.416 * * *$ & $-.385 * * *$ \\
\hline año2 & & & $.331 * * *$ & $.334 * * *$ & $.345 * * *$ \\
\hline Constante & $6.954 * * *$ & $7.426 * * *$ & $7.024 * * *$ & $7.022 * * *$ & $7.008 * * *$ \\
\hline Observaciones & 27254 & 24258 & 51512 & 51512 & 51512 \\
\hline $\mathrm{R}^{2}$ & .337 & .414 & .489 & .489 & .405 \\
\hline Individuos & & & & 27888 & 27888 \\
\hline
\end{tabular}

Nota. Las regresiones incluyen además controles sobre el nivel de estudios de los padres, universidad a distancia, discapacidad reconocida superior al 33\%, nacionalidad extranjera, Comunidad Autónoma y titulación.

$* * * \mathrm{p}<.01, * * \mathrm{p}<.05, * \mathrm{p}<.1$

Fuente. Encuesta de Inserción Laboral de Titulados Universitarios de 2019 (INE). Elaboración propia

Al objeto de estudiar la robustez de los resultados obtenidos en la primera parte del análisis, en la Tabla 6 se muestran la estimación de las ecuaciones de ingresos combinando los distintos indicadores de desajuste educativo y empleando dos estimadores alternativos: el modelo agrupado por MCO y el modelo de efectos fijos. En la primera columna se combinan las variables sobreeducación y desajuste horizontal. En comparación con los resultados obtenidos en la Tabla 3, la penalización de la sobreeducación en el modelo por MCO aumenta ligeramente del $13.0 \%$ al $13.8 \%$, mientras que el coeficiente del desajuste horizontal se vuelve positivo y estadísticamente significativo, aunque su tamaño es pequeño $(+1.7 \%)$. Es decir, una vez controlada la sobreeducación, los graduados que trabajan fuera de su área de estudio ganan más que los que trabajan en su propia área de especialización. 
A una conclusión similar llegan Somers et al. (2019) con relación al impacto del desajuste horizontal en los salarios.

Tabla 5

Estimación del efecto en los salarios del desajuste de habilidades

\begin{tabular}{|c|c|c|c|c|c|}
\hline & (1) & (2) & (3) & (4) & (5) \\
\hline variables & $\begin{array}{c}\text { Primer } \\
\text { empleo } \\
\text { (MCO) }\end{array}$ & $\begin{array}{c}\text { Empleo } \\
\text { actual } \\
\text { (MCO) }\end{array}$ & $\begin{array}{c}\text { Modelo } \\
\text { agrupado } \\
\text { (MCO) }\end{array}$ & $\begin{array}{l}\text { Efectos } \\
\text { aleatorios }\end{array}$ & $\begin{array}{c}\text { Efectos } \\
\text { fijos }\end{array}$ \\
\hline nousk & $-.048 * * *$ & $-.089 * * *$ & $-.062 * * *$ & $-.059 * * *$ & $-.035 * * *$ \\
\hline mujer & $-.053 * * *$ & $-.065 * * *$ & $-.060 * * *$ & $-.060 * * *$ & \\
\hline edad 30 a 34 & $-.010 *$ & -.006 & $-.009 * *$ & $-.010 * *$ & \\
\hline edad $>34$ & $.123 * * *$ & $.086 * * *$ & $.102 * * *$ & $.102 * * *$ & \\
\hline becagen & $-.035 * * *$ & $-.047 * * *$ & $-.040 * * *$ & $-.041 * * *$ & \\
\hline becaexc & $.020 \%$ & $.080 * * *$ & $.049 * * *$ & $.049 * * *$ & \\
\hline máster & & $.017 * * *$ & $.018 * * *$ & $.016 * * *$ & $.011 * *$ \\
\hline uprivada & $.041 * * *$ & $.052 * * *$ & $.045 * * *$ & $.045 * * *$ & \\
\hline parcial & $-.374 * * *$ & $-.527 * * *$ & $-.423 * * *$ & $-.416 * * *$ & $-.384 * * *$ \\
\hline año2 & & & $.330 * * *$ & $.333 * * *$ & $.344 * * *$ \\
\hline Constante & $6.954 * * *$ & $7.424 * * *$ & $7.025 * * *$ & $7.023 * * *$ & $7.010 * * *$ \\
\hline Observaciones & 27082 & 24261 & 51343 & 51343 & 51343 \\
\hline $\mathrm{R}^{2}$ & .337 & .416 & .490 & .489 & .406 \\
\hline Individuos & & & & 27862 & 27862 \\
\hline
\end{tabular}

Nota. Las regresiones incluyen además controles sobre el nivel de estudios de los padres, universidad a distancia, discapacidad reconocida superior al 33\%, nacionalidad extranjera, Comunidad Autónoma y titulación.

$* * * \mathrm{p}<.01, * * \mathrm{p}<.05, * \mathrm{p}<.1$

Fuente. Encuesta de Inserción Laboral de Titulados Universitarios de 2019 (INE). Elaboración propia

En la columna 2 se combina la sobreeducación con el desajuste de habilidades. La penalización salarial de la sobreeducación apenas varía mientras que el desajuste de habilidades tiene un efecto cercano a 0 y estadísticamente no significativo. Cuando se omite el desajuste educativo y se incluyen en la ecuación de ingresos los indicadores de desajuste horizontal y de no utilización de las habilidades, ambas variables se muestran estadísticamente significativas y recogen parcialmente la 
penalizacion de ingresos de la sobreeducación (véase la tercera columna de la Tabla 6). Trabajar fuera del área de estudios tiene una penalizacion del $3.1 \%$ mientras que no usar los conocimientos y habilidades adquiridos en la universidad reduce la retribución en un 4.2\%. Por último, cuando se incluyen las tres variables en el modelo con datos agrupados, la penalización de la sobreeducación se vuelve a situar en el $13.7 \%$, trabajar fuera del área de estudios aumenta los ingresos en un $2.1 \%$, mientras que no usar los conocimientos y habilidades adquiridos en la universidad no tiene un efecto estadísticamente significativo. En conclusión, la sobreeducación muestra una penalización salarial notable en los salarios de los graduados mientras que trabajar fuera del área de estudios tiene un impacto positivo en los ingresos, siempre y cuando el desajuste horizontal no resulte de trabajar en empleos que no requieran estudios universitarios.

Las cuatro últimas columnas reproducen el mismo ejercicio empleando el estimador de efectos fijos. Partiendo de la base de que la estimación de efectos fijos reduce ligeramente el tamaño de los coeficientes en comparación con la estimación por MCO, los resultados son muy consistentes. En todas las ecuaciones en las que se incluye la variable sobreeducación, el coeficiente estimado siempre es negativo y estadísticamente significativo, reduciendo los salarios de los titulados entre un $-8.1 \%$ y un $-9.4 \%$. Cuando la variable anterior se combina con el desajuste horizontal, trabajar fuera del área de estudios eleva los salarios entre un 3.0 y un 3.6\%. Por último, el desajuste de habilidades muestra un efecto negativo y estadísticamente significativo en la especificación en la que se omite la sobreeducación. Por tanto, una vez controladas las diferencias de capacidad, la sobreeducación se asocia de una forma robusta con la reducción de los ingresos de los titulados, mientras que desempeñar un trabajo fuera del área de estudios no reduce los salarios, sino que al contrario, se traduce en una mejora de las retribuciones. 
Tabla 6

Estimación del efecto en los salarios de los tres indicadores de desajuste educativo

\begin{tabular}{|c|c|c|c|c|c|c|c|c|}
\hline & (1) & (2) & (3) & (4) & (5) & (6) & (7) & (8) \\
\hline $\begin{array}{l}\text { VARIA- } \\
\text { BLES }\end{array}$ & $\begin{array}{c}\text { Modelo } \\
\text { agrupado } \\
\text { (MCO) }\end{array}$ & $\begin{array}{c}\text { Modelo } \\
\text { agrupado } \\
\text { (MCO) }\end{array}$ & $\begin{array}{c}\text { Modelo } \\
\text { agrupado } \\
\text { (MCO) }\end{array}$ & $\begin{array}{c}\text { Modelo } \\
\text { agrupado } \\
\text { (MCO) }\end{array}$ & $\begin{array}{c}\text { Efectos } \\
\text { fijos }\end{array}$ & $\begin{array}{c}\text { Efectos } \\
\text { fijos }\end{array}$ & $\begin{array}{c}\text { Efectos } \\
\text { fijos }\end{array}$ & $\begin{array}{c}\text { Efectos } \\
\text { fijos }\end{array}$ \\
\hline Over & $-.148 * * *$ & $-140 * * *$ & & $-.147 * * *$ & $-.099 * * *$ & $-.085 * * *$ & & $-.096 * * *$ \\
\hline Horiz & $.017 * * *$ & & $-.031 * * *$ & $.021 * * *$ & $.030 * * *$ & & -.006 & $.035 * * *$ \\
\hline Nousk & & .003 & $-.043 * * *$ & -.007 & & .006 & $-.032 * * *$ & -.011 \\
\hline Mujer & $-.061 * * *$ & $-.061 * * *$ & $-.060 * * *$ & $-.061 * * *$ & & & & \\
\hline $\begin{array}{l}\text { edad } 30 \\
\text { a } 34\end{array}$ & -.002 & -.002 & $-.008^{* *}$ & -.002 & & & & \\
\hline $\begin{array}{l}\text { edad > } \\
34\end{array}$ & $.103 * * *$ & $.104 * * *$ & $.104 * * *$ & $.104 * * *$ & & & & \\
\hline Becagen & $-.034 * * *$ & $-.035 * * *$ & $-.040 * * *$ & $-.034 * * *$ & & & & \\
\hline Becaexc & $.044 * * *$ & $.044 * * *$ & $.049 * * *$ & $.044 * * *$ & & & & \\
\hline Máster & $.008^{*}$ & $.008 *$ & $.017 * * *$ & $.008 *$ & .009 & .009 & $.011^{* * *}$ & .009 \\
\hline Uprivada & $.041 * * *$ & $.040 * * *$ & $.045 * * *$ & $.040 * * *$ & & & & \\
\hline Parcial & $-.405 * * *$ & $-.404 * * *$ & $-.421 * * *$ & $-.405 * * *$ & $-.374 * * *$ & $-.373 * * *$ & $-.383 * * *$ & $-.373 * * *$ \\
\hline año2 & $.322 * * *$ & $.323 * * *$ & $.330 * * *$ & $.322 * * *$ & $.338 * * *$ & $.338 * * *$ & $.345^{* * *}$ & $.338 * * *$ \\
\hline Constant & $7.041 * * *$ & $7.044^{* * *}$ & $7.028 * * *$ & $7.042 * * *$ & $7.021 * * *$ & $7.024 * * *$ & $7.011 * * *$ & $7.022^{* * * *}$ \\
\hline $\begin{array}{l}\text { Observa- } \\
\text { ciones }\end{array}$ & 51380 & 51188 & 51229 & 51100 & 51380 & 51188 & 51229 & 51100 \\
\hline $\mathrm{R}^{2}$ & .502 & .502 & .490 & .502 & .422 & .422 & .406 & .422 \\
\hline $\begin{array}{l}\text { Indivi- } \\
\text { duos }\end{array}$ & & & & & 27849 & 27811 & 27812 & 27773 \\
\hline
\end{tabular}

Nota. Las regresiones incluyen además controles sobre el nivel de estudios de los padres, universidad a distancia, discapacidad reconocida superior al 33\%, nacionalidad extranjera, Comunidad Autónoma y titulación.

$* * * \mathrm{p}<.01, * * \mathrm{p}<.05, * \mathrm{p}<.1$

Fuente. Encuesta de Inserción Laboral de Titulados Universitarios de 2019 (INE). Elaboración propia

Los resultados de la estimación de los modelos de efectos fijos sugieren que la sobreeducación no se explica por las diferencias o escasez de habilidades o conocimientos de los titulados, ya que cuando se controla la heterogeneidad individual, la penalización salarial sigue siendo elevada y estadísticamente significativa. Además, aunque existe una correlación elevada entre las tres variables con las que medimos el desajuste (horizontal, vertical y de habilidades), la relación entre las tres variables es compleja. La mayoría de los graduados sobreeducados no utilizan los conocimientos adquiridos en la universidad, pero mientras que en unos casos el vínculo 
es muy claro, como cuando un universitario trabaja como administrativo o más aún cuando trabaja de camarero, en otros casos se trata más bien de una cuestión de grado (un economista ocupado en la oficina de un banco). El problema se complica cuando se estudia el desajuste horizontal. Cuando se analiza de forma aislada, trabajar fuera del área de estudios propia de la titulación se asocia a una reducción de los salarios (véase la Tabla 4). Esta penalización salarial se explica porque los trabajadores sobreeducados consideran mayoritariamente que trabajan fuera del área de su área de estudios (71.4\%). Sin embargo, una vez que se controla la sobreeducación, trabajar fuera del área de estudios incrementa el salario de los titulados, como por ejemplo cuando un físico o un matemático trabajan en el sector financiero. Estos titulados trabajan fuera del ámbito propio de las ciencias físicas o de las matemáticas, mayoritariamente afirman que no utilizan los conocimientos o habilidades adquiridos en la universidad, y sin embargo, no sufren una penalización salarial sino que habitualmente ganan más que otros compañeros de estudios que trabajan en otros sectores como la investigación o la enseñanza. Por tanto, mientras que la sobreeducación limita la productividad y los salarios de los titulados, el desajuste horizontal y el desajuste de habilidades en muchas ocasiones no producen el mismo efecto, en la medida en que se transfieren conocimientos y habilidades generales valorados y recompensados en otras ocupaciones cualificadas.

En la Tabla 7 se muestran los efectos marginales de un modelo logit en el que se estudia los determinantes de los tres indicadores con los que se ha medido el desajuste educativo. En la columna 1 se presentan los resultados de los determinantes del desajuste vertical, en la 2 los del desajuste horizontal y en la 3 los del desajuste de habilidades. El ejercicio empírico se centra en la situación laboral de los graduados en el momento actual, es decir, en el año 2019, transcurridos 5 años desde su transición desde la universidad al mercado de trabajo. Por tanto, el análisis pretende identificar aquellas características correlacionadas con el desajuste educativo que tiene un carácter más permanente.

Tabla 7

Determinantes del desajuste educativo. Efectos marginales

\begin{tabular}{|c|c|c|c|}
\hline VARIABLES & $\begin{array}{c}\text { Desajuste } \\
\text { vertical }\end{array}$ & $\begin{array}{c}\text { Desajuste } \\
\text { horizontal }\end{array}$ & $\begin{array}{l}\text { Desajuste de } \\
\text { habilidades }\end{array}$ \\
\hline $\operatorname{Pr}(y=1)$ & .164 & .219 & .211 \\
\hline mujer & .001 & -.009 & $.015 *$ \\
\hline edad 30 a 34 & $.046 * * *$ & $.043 * * *$ & $.027 * * *$ \\
\hline edad $>34$ & .014 & $.038^{* * * *}$ & -.012 \\
\hline paduni & $-.042 * * *$ & -.002 & -.010 \\
\hline
\end{tabular}




\begin{tabular}{|c|c|c|c|}
\hline VARIABLES & $\begin{array}{c}\text { Desajuste } \\
\text { vertical }\end{array}$ & $\begin{array}{c}\text { Desajuste } \\
\text { horizontal }\end{array}$ & $\begin{array}{c}\text { Desajuste de } \\
\text { habilidades }\end{array}$ \\
\hline maduni & $-.019 * * *$ & $-.019 *$ & -.007 \\
\hline padpri & $.012 *$ & $.013^{* *}$ & .007 \\
\hline madpri & .001 & -.001 & .004 \\
\hline becagen & $.034 * * *$ & $.012 *$ & .010 \\
\hline becaexc & $-.057 * * *$ & $-.050 * * *$ & $-.073 * * *$ \\
\hline máster & $-.110 * * *$ & $-.074 * * *$ & $-.061 * * *$ \\
\hline uprivada & $-.044 * * *$ & $-.042 * * *$ & $-.060 * * *$ \\
\hline discapacidad & -.027 & .001 & .033 \\
\hline extranjero & .025 & .014 & -.005 \\
\hline uni_distancia & .021 & $.085 * * *$ & $.091 * * *$ \\
\hline uni_amb_nacional & -.001 & -.013 & $-.064 * * *$ \\
\hline Andalucía & $.040 * *$ & -.010 & -.009 \\
\hline Aragón & $.023 *$ & -.003 & .001 \\
\hline Asturias & .029 & -.003 & -.005 \\
\hline Baleares & -.000 & -.035 & -.025 \\
\hline Canarias & $.043 * *$ & .015 & -.014 \\
\hline Cantabria & .023 & -.024 & -.019 \\
\hline Castilla y León & .013 & $-.033 * *$ & -.019 \\
\hline Castilla-La Mancha & .031 & .003 & -.007 \\
\hline Cataluña & $-.025 * *$ & $-.047 * * *$ & $-.056 * * *$ \\
\hline C. Valenciana & $.034 * *$ & $-.027 * *$ & -.021 \\
\hline Extremadura & $.056 * * *$ & $.042 *$ & .017 \\
\hline Galicia & .015 & -.022 & $-.049 * * *$ \\
\hline Murcia & $.052 * *$ & -.011 & $-.029 *$ \\
\hline Navarra & .008 & $-.039 * *$ & -.031 \\
\hline País Vasco & $.027 *$ & -.015 & $-.030 * *$ \\
\hline Rioja (La) & -.039 & $-.071 * * *$ & $-.093 * * *$ \\
\hline Educación (Otros est.) & -.001 & .000 & $.015 * * *$ \\
\hline Artes (Otros est.) & $.204 * * *$ & $.208 * * *$ & $.216 * * *$ \\
\hline Humanidades & $.207 * * *$ & $.300 * * *$ & $.309 * * *$ \\
\hline Lenguas & $.030 * * *$ & $.110 * * *$ & $.076 * * *$ \\
\hline Cienc. sociales/comport. & $.115 * * *$ & $.305 * * *$ & $.275 * * *$ \\
\hline
\end{tabular}




\begin{tabular}{|c|c|c|c|}
\hline VARIABLES & $\begin{array}{c}\text { Desajuste } \\
\text { vertical }\end{array}$ & $\begin{array}{c}\text { Desajuste } \\
\text { horizontal }\end{array}$ & $\begin{array}{l}\text { Desajuste de } \\
\text { habilidades }\end{array}$ \\
\hline Periodismo/documentación & $.067 * * *$ & $.114 * * *$ & $.147 * * *$ \\
\hline Negocios/administración & $.052 * * *$ & $.083 * * *$ & $.142 * * *$ \\
\hline Ciencias de la vida & $.030 * * *$ & $.012 * *$ & $.054 * * *$ \\
\hline Medio ambiente & $.073 * * *$ & $.193 * * *$ & $.241 * * *$ \\
\hline Cienc. quím./físic./geol. & $.040 * * *$ & $.054 * * *$ & $.093 * * *$ \\
\hline Matemáticas/estad. & $-.050 * * *$ & $-.033 * * *$ & $.035 * * *$ \\
\hline Informática & $-.069 * * *$ & $-.147 * * *$ & $-.124 * * *$ \\
\hline Ingeniería/prof. afines & $-.077 * * *$ & $-.068 * * *$ & $.012 * * *$ \\
\hline Ind. manuf./producción & $-.051 * * *$ & $.038 * * *$ & $.109 * * *$ \\
\hline Arquit./construcción & $-.046 * * *$ & $-.011 * * *$ & $.021 * * *$ \\
\hline Agricultura/ganadería & .008 & .009 & $.055 * * *$ \\
\hline Silvicultura & $.063 * * *$ & $.085 * * *$ & $.131 * * *$ \\
\hline Veterinaria & $-.117 * * *$ & $-.140 * * *$ & $-.121 * * *$ \\
\hline Salud (Otros est,) & $-.109 * * *$ & $-.106 * * *$ & $-.080 * * *$ \\
\hline Servicios sociales & $.011 * *$ & $-.017 * * *$ & $.018 * * *$ \\
\hline Serv./(Otros est.) & $-.027 * * *$ & .009 & $.023 * * *$ \\
\hline Form. docentes/e. inf. & $.051 * * *$ & -.000 & $.076 * * *$ \\
\hline Form. docentes/e. pri. & $-.053 * * *$ & $-.057 * * *$ & $.028 * * *$ \\
\hline Técn. audiov./medios com. & $.185 * * *$ & $.200 * * *$ & $.238 * * *$ \\
\hline Economía & $.050 * * *$ & $.022 * * *$ & $.124 * * *$ \\
\hline Psicología & $.059 * * *$ & $.065 * * *$ & $.058 * * *$ \\
\hline Dirección/administración & $.053 * * *$ & .003 & $.051 * * *$ \\
\hline Medicina & $-.171 * * *$ & $-.235 * * *$ & $-.185 * * *$ \\
\hline Enfermería & $-.156 * * *$ & $-.190 * * *$ & $-.189 * * *$ \\
\hline Activ. físicas/deport. & $.128 * * *$ & $.077 * * *$ & $.106 * * *$ \\
\hline Viajes/turismo/ocio & $.185 * * *$ & $.159 * * *$ & $.221 * * *$ \\
\hline Observaciones & 24773 & 24755 & 24753 \\
\hline
\end{tabular}

Nota. $* * * \mathrm{p}<.01, * * \mathrm{p}<.05, * \mathrm{p}<.1$

Fuente. Encuesta de Inserción Laboral de Titulados Universitarios de 2019 (INE). Elaboración propia

Se va a realizar un examen más detenido de los determinantes de la sobreeducación, en la medida en que es la forma de desajuste educativo que 
genera una mayor penalización en los salarios de los titulados y, tanto desde el punto de vista privado como social, podría representar un mayor grado de despilfarro de recursos. En primer lugar habría que señalar que el desajuste se asocia a distintas variables indicativas del estatus socioeconómico de las familias de los universitarios. Tomando como referencia un graduado con las características medias de la muestra empleada, se obtiene que la probabilidad de estar sobreeducado en el empleo actual asciende al 16.4\%. Pues bien, esa probabilidad media puede variar en 7.3 puntos porcentuales dependiendo del nivel de estudios de los padres. Los titulados cuyo padre (-4.2 puntos porcentuales —en adelante p.p.-) y madre (-1.9 p.p.) tienen estudios universitarios muestran una menor probabilidad de estar sobreeducados, mientras que aquellos que tienen un padre con estudios primarios o inferior (+1.2 p.p.) tienen una mayor probabilidad de estar sobreeducados. En la misma línea KUCEL y Vilalta-Bufí (2019) y CapsadaMunsech, Queralt (2020) encuentran que el nivel educativo de los padres influye en la probabilidad de estar sobreeducado.

Otras variables que indirectamente nos pueden informar del estatus socioeconómico del hogar son el disfrute de una beca general, estudiar en una universidad privada o realizar un máster. En cuanto a las becas generales hay que señalar que se dirigen a aquellos estudiantes en los que la renta del hogar no supera un determinado umbral. Disfrutar de una beca general aumenta en 3.4 puntos porcentuales la probabilidad de estar sobreeducado. En la misma línea, haber estudiado en una universidad privada reduce en 4.4 puntos porcentuales la probabilidad de estar sobreeducado, mientras que la realización de un máster reduce en 11.0 puntos porcentuales el desajuste educativo vertical. En este sentido, habría que subrayar que aunque los másteres tienen un impacto muy pequeño en los salarios de los titulados (elevan la retribución entre un 1 y un $2 \%$ ) muestran un impacto muy notable en la reducción del desajuste educativo.

Por último, habría que señalar que se identifica cierto patrón regional en el análisis de los determinates de la sobreeducación, donde los titulados de las regiones con un menor nivel de desarrollo (Andalucía, Canarias, Extremadura y Murcia) muestran una probabilidad al menos 4.0 puntos porcentuales superior de estar sobreeducados que los de Madrid, la Comunidad Autónoma de referencia. A su vez la única región que muestra un efecto marginal negativo es Cataluña, donde la probabilidad de estar sobreeducado se reduce en 2.5 puntos porcentuales en comparación con Madrid.

La desigualdad de oportunidades, en términos del entorno familiar de procedencia del graduado o de la región en la que vive, es un factor importante a la hora de entender el fenómeno de la sobreeducación en el 
sistema universitario español. No obstante, el factor que genera un mayor impacto en la probabilidad de estar sobreeducado es el campo de estudios o la titulación cursada por el graduado. En la Tabla 7 se muestran los resultados para los 32 ámbitos de estudios definidos en la encuesta, tomando como referencia el ámbito de estudio de Derecho. Por mencionar unos ejemplos, los graduados de Artes (+20.4 p.p.) y Humanidades (+20.7 p.p.) muestran una probabilidad notablemente superior de estar sobreeducados que los de Derecho. Otros ámbitos de estudio que se asocian positivamente con la sobreeducación son Técnicas Audiovisuales/Medios de Comunicación (+18.5 p.p.) y Viajes/Turismo/Ocio (+18.5 p.p.). En el polo opuesto, los graduados de Medicina (-17.1 p.p.) y Enfermería (-15,6 p.p.) muestran una probabilidad inferior de sufrir desajuste vertical. Otros ámbitos de estudio con resultados positivos son Matemáticas/Estadística (-5.0 p.p.), Informática (-6.9 p.p.), Ingeniería (-7.7 p.p.), Industria Manufacturera/Producción (-5.1 p.p.), Arquitectura/Construcción (-4.6 p.p.), Veterinaria (-11.7 p.p.) y Salud (Otros estudios) (-10.9 p.p.). Por tanto, dependiendo del ámbito de estudios elegido, la incidencia de la sobreeducación puede variar hasta en 38 puntos porcentuales si se comparan los titulados de algunos campos de Ciencias de la Salud con las de otros de las ramas de Ciencias Sociales y Humanidades.

El patrón de resultados descrito con relación al desajuste vertical se mantiene cuando se estudia el desajuste horizontal y el de habilidades. En ambos casos pierden cierto peso las variables que caracterizan el entorno socioeconómico del graduado y en cambio se acentúan las diferencias por campos de estudio. Por mencionar algunos ejemplos extremos, entre los titulados de Medicina (-23.5 p.p.) y los de Humanidades (+30.0 p.p.) o los de Ciencias Sociales/Comportamiento (+30.5 p.p.) la probabilidad de trabajar fuera del área de estudios varía en más de 50 puntos porcentuales. En la misma línea, mientras que entre los titulados de Enfermería la probabilidad de no usar los conocimientos y habilidades adquiridos en la universidad se reduce en 18,9 puntos porcentuales en comparación con los graduados de Derecho, la probabilidad aumenta en 30.9 puntos porcentuales entre los graduados de Humanidades.

\section{CONCLUSIONES}

Los resultados del análisis empírico indican que la sobreeducación tiene un impacto económicamente sustancial y estadísticamente significativo, que sugiere que las características de los empleos limitan el aprovechamiento del potencial productivo de nuestros titulados universitarios. Este resultado es consistente con lo obtenido por Nieto y Ramos (2017) con relación al caso español. La heterogeneidad en las habilidades explica parcialmente la penalización salarial del desajuste educativo vertical, pero para mejorar 
las expectativas profesionales de nuestros graduados universitarios se debe hacer más hincapié en el lado de la demanda, que no ha generado suficientes empleos cualificados para acoger a la oferta creciente de titulados que ha producido el sistema universitario español en las últimas décadas. Esta conclusión tiene una lectura especial en un momento de grave crisis económica como el que nos encontramos en la actualidad como consecuencia de la COVID-19, que afecta desproporcionadamente al mercado laboral de los jóvenes.

Del análisis comparado del impacto en los salarios de los tres tipos de desajuste se concluye que, aunque los tres están estrechamente relacionados, el que tiene implicaciones económicas más graves es el desajuste vertical. Trabajar fuera del área de estudios propia del titulado o no utilizar los conocimientos y habilidades adquiridos en la universidad tiene una repercusión negativa en las retribuciones de los titulados únicamente cuando resultan del desajuste vertical. De hecho, una vez que se controla la sobreeducación, trabajar fuera del área de estudios del titulado tiene un impacto positivo en los salarios, lo que sugiere la transferibilidad de algunas habilidades y conocimientos fuera del campo de conocimiento propio del graduado.

La desigual incidencia del desajuste educativo por ámbitos de conocimiento invita a trabajar igualmente por el lado de la oferta. Como se ha señalado en distintas ocasiones, se debe mejorar el asesoramiento de los estudiantes en el momento de elegir los estudios. A su vez se debe promover la investigación, el debate y la difusión de los resultados de inserción laboral de nuestros universitarios. En este sentido habría que hacer especial hincapié en que la información y la orientación académica llegue a los estudiantes procedentes de entornos socioeconómicos menos favorables, que presentan una mayor probabilidad de estar sobreeducados. Igualmente se debe promover una comunicación más fluida entre las instituciones de enseñanza superior y los empleadores, para mejorar el conocimiento acerca de las habilidades y competencias demandadas por las empresas. No obstante, no se debe perder de vista en que si no se fortalece la demanda, se podrá mejorar la posición relativa de unos individuos frente a otros en la cola de contratación de la mano de obra cualificada descrita por Thurow (1976), sin obtener un efecto neto significativo en términos de reducción del problema. 


\section{REFERENCIAS BIBLIOGRÁFICAS}

Alba-Ramírez, A. (1993). Mismatch in the Spanish labor market. Overeducation? Journal of Human Resources, 18(2), 259-278.

Alba-Ramírez, A., \& Blazquez, M. (2002). Types of job match, overeducation and labour mobility in Spain. En F. Buchel, A. de Grip, and A. Mertens (Eds.) Overeducation in Europe: Current issues in theory and policy (pp. 65-90), Cheltenham and Northampton.

Allen, J., \& van der Velden, R. (2001). Educational mismatches versus skill mismatches: effects on wages, job satisfaction, and on-the-job search, Oxford Economic Papers, 53(3), 434-452. https://doi.org/10.1093/ oep/53.3.434

Allen, J., \& de Weert, E. (2007). What do educational mismatches tell us about skill mismatches? A crosscountry analysis. European Journal of Education, 42(1), 59-73. https://doi. org/10.1111/j.1465-3435.2007.00283.x

Almasi, P., Hadavand, A., Thomas, S., \& Gharehgozli, O. (2020). Relevance of education to occupation: a new empirical approach based on college courses. Education Economics, 28(4), 370-383. https://doi.org/10.1080/09645 292.2020.1749233

Banerjee, R., Verma, A., \& Zhang, T. T. (2019). Brain gain or brain waste? Horizontal, vertical, and full job-education mismatch and wage progression among skilled immigrant men in Canada. International Migration Review, 53(3), 646-670. https://doi. org/10.1177/0197918318774501

Battu, H., Belfield, C. R., \& Sloane, P. J. (1999). Overeducation amog graduates: a cohort view. Education Economics, 7(1), 21-38.
Bauer, T. K. (2002). Educational mismatch and wages: A panel analysis. Economics of Education Review, 21(3), 221-229. https://doi.org/10.1016/ S0272-7757(01)00004-8

Becker, G. (1964). Human capital: a theoretical and empirical analysis, with special reference to education, Columbia University Press for the National Bureau of Economic Researc.

Biagi, F., Castaño-Muñoz, J. \& Di Pietro, G. (2020). Mismatch between Demand and Supply among higher education graduates in the EU. EUR $30121 \mathrm{EN}$, Publications Office of the European Union. https://doi.org/10.2760/003134

Budría, S. \& Moro-Egido, A. I. (2008). Education, educational mismatch, and wage inequality: Evidence for Spain. Economics of Education Review 27(3), 332-341. https://doi.org/10.1016/j. econedurev.2006.10.005

Capsada-Munsech, Q. (2020). Overeducation, skills and social background: the influence of parental education on overeducation in Spain, Compare: a journal of comparative and international education, 50(2), 216236. https://doi.org/10.1080/03057925 .2019 .1579085

Chevalier, A. (2003). Measuring overeducation. Economica, 70(279), 509-531. https://doi.org/10.1111/14680335.t01-1-00296

Choi, S. K., \& Hur, H. (2020). Does job mismatch affect wage and job turnover differently by gender? Education Economics, 28(3), 291-310. https://doi. org/10.1080/09645292.2019.1710464

Di Pietro, G., \& Urwin, P. (2006). Education and skills mismatch in the Italian graduate labour market. Applied 
Economics, 38(1), 79-93. https://doi. org/10.1080/00036840500215303

Dolton, P., \& Silles, M. (2008). The effects of overeducation on earnings in the graduate labour market. Economics of Education Review, 27(2), 125-139. https://doi.org/10.1016/j. econedurev.2006.08.008

Dolton, P., \& Vignoles, A. (2000). The incidence and effects of overeducation in the UK graduate labour market, Economics of Education Review, 19(2), 179-198. https://doi.org/10.1016/ S0272-7757(97)00036-8

Duncan, G., \& Hoffman, S. (1981). The incidence and wage effects of overeducation. Economics of Education Review, 1(1), 75-86.

\section{EUROSTAT (2020). Skills mismatch experimental indicators. Methodological note. https:// n9.cl/672fb}

Freeman, R. B. (1996). The Overeducated American. Academic Press.

Frenette, M. (2004). The overqualified Canadian graduate: the role of the academic program in the incidence, persistence, and economic returns to overqualification. Economics of Education Review, 23(1), 2945. https://doi.org/10.1016/S02727757(03)00043-8

Garcia-Mainar I., \& Montuenga V. M. (2019). The signalling role of over-education and qualifications mismatch, Journal of Policy Modeling, 41(1), 99-119. https://doi.org/10.1016/j. jpolmod.2019.02.015

García-Serrano, C., \& Malo, M. A. (1996). Desajuste educativo y movilidad laboral en España. Revista de Economía Aplicada, 11(4), 105-131.

García-Montalvo, J., \& Peiró, J. M. (2009). Análisis de la sobrecualificación y la flexibilidad laboral. Fundación Bancaja.

Green, F., \& Henseke, G. (2021). Europe's evolving graduate labour markets: supply, demand, underemployment and pay. Journal for Labour Market Research, 55(2), 1-13. https://doi. org/10.1186/s12651-021-00288-y

Green, F., \& McIntosh, S. (2007). Is there a genuine under-utilization of skills among the over-qualified? Applied Economics, 39(4), 427-439. https://doi. org/10.1080/00036840500427700

Green, F., McIntosh, S., \& Vignoles, A. (1999). Overeducation and Skills. Clarifying the Concepts. Center for Economic Performance, Discussion paper, (435).

Green, F. \& Zhu, Y. (2010). Overqualification, job dissatisfaction, and increasing dispersion in the returns to graduate education. Oxford Economic Papers, 62(4), 740-763. https://doi.org/10.1093/oep/gpq002

Hartog, J. (2000). Overeducation and earnings: where are we, where should we go? Economics of Education Review, 19(2), 131-147. https://doi. org/10.1016/S0272-7757(99)00050-3

INE (2020). Encuesta de Inserción Laboral de los Titulados Universitarios EILU-2019. https://n9.cl/35dww

Iriondo, I. \& Pérez-Amaral, T. (2016). The effect of educational mismatch on wages in Europe, Journal of Policy Modeling, 38(2), 304-323. https://doi. org/10.1016/j.jpolmod.2015.12.008

Korpi, T., \& Tåhlin, M. (2009). Education mismatch, wages, and wage growth: overeducation in Sweden 1974-2000. Labour Economics, 16(2), 183-193. https://doi.org/10.1016/j. labeco.2008.08.004 
Kucel, A., \& Vilalta-Bufi, M. (2019). University program characteristics and education-job mismatch. $B E$ Journal of Economic Analysis \& Policy, 19(4), 1-12. https://doi.org/10.1515/ bejeap-2019-0083

Leuven, E., \& Oosterbeek, H. (2011). Overeducation and mismatch in the labor market. En E. A. Hanushek, S. Machin, \& L. Woessmann (Eds.), Handbook of the economics of education (Vol. 4; pp. 283-326).

Li, I. W., Harris, M., \& Sloane, P. J. (2018). Vertical, horizontal and residual skills mismatch in the Australian graduate Labour Market. Economic Record, 94(306), 301315. https://doi.org/10.1111/14754932.12413

McGuinness, S. (2006). Overeducation in the labour market. Journal of Economic Surveys, 20(3), 387418. https://doi.org/10.1111/j.09500804.2006.00284.x

McGuinness, S., Pouliakas, K., \& Redmond, P. (2018). Skills mismatch: concepts, measurement and policy approaches. Journal of Economic Surveys, 32(4), 985-1015. https://doi. org/10.1111/joes.12254

McGuinness, S., \& Sloane, P. J. (2011). Labour market mismatch among UK graduates: An analysis using REFLEX data, Economics of Education Review, 30(1), 130-145. https://doi. org/10.1016/j.econedurev.2010.07.006

Moro-Egido, A. I. (2020). Gender differences in skill mismatches. Hacienda Pública Española-Review of Public Economics, 235(4), 29-60.

Murillo, I.P., Rahona, M., \& Salinas, M.M. (2012). Effects of educational mismatch on private returns to education: An analysis of the Spanish case (1995-2006). Journal of Policy
Modeling, 34(5), 646-659. https://doi. org/10.1016/j.jpolmod.2011.07.012

Nieto, S., \& Ramos, R. (2017). Overeducation, skills and wage penalty: Evidence for Spain using PIAAC data. Social Indicators Research, 134(1), 219-236. https://doi. org/10.1007/s11205-016-1423-1

Nordin, M., Persson, I., \& Rooth, D. (2010). Education-occupation mismatch: Is there an income penalty? Economics of Education Review, 29(6), 1047-1059. https://doi.org/10.1016/j. econedurev.2010.05.005

Park, K. (2018). Vertical and horizontal mismatches and career mobility: evidence from female college graduates. Asian-Pacific Economic Literature, 32(2), 109-125. https://doi. org/10.1111/apel.12246

Rodriguez-Esteban, A., \& Vidal, J. (2020). Influence of educational factors on the education-job match in men and women. Relieve-Revista Electrónica De Investigación y Evaluación Educativa, 26(1). https:// doi.org/10.1111/apel.12246

Rodriguez-Esteban, A., Vidal, J., \& Vieira, M. J. (2019). An analysis of the employability of Spanish graduates through the Horizontal Match. Revista de Educación 384(2), 229254. https://doi.org/10.4438/1988592X-RE-2019-384-411

Robst, J. (2007). "Education, college major, and job match: Gender differences in reasons for mismatch", Education Economics, 15(2), 159-175. https://doi. org/10.1080/09645290701263070

Rubb, S. (2003). Overeducation: a short or long run phenomenon for individuals? Economics of Education Review, 22(4), 389-394. https://doi. org/10.1016/S0272-7757(02)00052-3 
Rudakov, V., Figueiredo, H., Teixeira, P., \& Roshchin, S. (2019). The impact of horizontal job-education mismatches on the earnings of recent university graduates in Russia. IZA Discussion Paper N. 12407.

Sattinger, M. (1993). Assignment models of the distribution of earnings. Journal of Economic Literature, 31(2), 831-880.

Sicherman, N. (1991). Overeducation in the labor market. Journal of Labor Economics, 9(2), 101-122.

Sicherman, N., \& Galor, O. (1990). A theory of career mobility. Journal of Political Economy, 98(1), 169-192.

Somers, M. A., Cabus, S. J., Groot, W., \& van den Brink, H. M. (2019). Horizontal mismatch between employment and field of education: evidence from a systematic literature review. Journal of Economic Surveys, 33(2), 567-603. https://doi.org/10.1111/ joes. 12271

Thurow, L.C. (1976). Generating inequality: Mechanisms of distribution in the U.S. economy. Basic Books.

Tsai, Y. (2010). Returns to overeducation: A longitudinal analysis of the U.S. labor market. Economics of Education Review, 29(4), 606-617. https://doi. org/10.1016/j.econedurev.2010.01.001

Veselinović, L., Mangafić, J., \& Turulja, L. (2020). The effect of education-job mismatch on net income: evidence from a developing country, Economic Research-Ekonomska Istraživanja, 33(1), 2648-2669. https://doi.org/10.10 80/1331677X.2020.1723427 


\section{PERFIL ACADÉMICO Y PROFESIONAL DEL AUTOR}

Iñaki Iriondo Múgica. ORCID: https://orcid.org/0000-0002-9576-2870

Profesor Titular de Universidad en la UCM. Ha sido Visiting Scholar en Harvard y en Queen Mary University of London. Fue Vicedecano (2007/2011) y en la actualidad es Subdirector del Departamento de Economía Aplicada, Estructura e Historia. Su investigación se centra en el ámbito de la economía del trabajo y de la educación. E-mail: iriondo@ccee.ucm.es

Fecha Recepción del Artículo: 31. Marzo. 2021

Fecha Modificación del Artículo: 23. Mayo. 2021

Fecha Aceptación del Artículo: 26. Mayo. 2021

Fecha Revisión para Publicación: 13. Septiembre.2021 